\title{
Traição e re-memoração. Reflexões sobre a experiência estética com base na Fenomenologia do espírito*
}

Giorgia Cecchinato

Professora adjunta de Estética na UFMG

* Esse é o texto da apresentação que fiz em novembro 2009 na USP no quadro da "Jornada de Idealismo Alemão", organizada e dirigida com diligência e hospitalidade por Márcio Suzuki. No seu núcleo central, este texto retoma e elabora um outro artigo meu publicado em italiano: G. CECCHINATO. Er-innerung e arte. Verifiche, 2009, p. 207-29. 



\section{Introdução}

No capítulo dedicado ao saber absoluto, concluindo o caminho fenomenológico, Hegel refere-se à re-memoração (Er-innerung) como condição da própria Fenomenologia do espírito. Então proponho analisar esse conceito em seu contexto originário e usá-lo como chave para compreender mais profundamente a concepção hegeliana da experiência artística ${ }^{1}$, a qual será depois desenvolvida em toda a sua riqueza em seus Cursos de estética. Por meio dessa leitura será também possível obter alguns instrumentos conceituais úteis para uma compreensão mais abrangente da experiência artística em geral, e mesmo aquela da arte contemporânea, a qual talvez possa suscitar perplexidade.

\section{Saber absoluto e Er-innerung}

No último capítulo da Fenomenologia, intitulado "O saber absoluto", depois de ter resumido as etapas mais significativas do percurso feito até então, Hegel mostra como, com base na integração recíproca da boa-consciência (Gewissen) e da religião, sobressai o saber absoluto. A boa-consciência é a figura mais alta no momento do "Espírito", a qual, enquanto sujeito, em si mesmo portador do valor moral universal, reconhece em si a genuína unidade da autoconsciência e essência universal; ela já é porém autointuição do absoluto². O Gewissen já está na forma genuína do conceito, transparente a si mesmo, mas seu conteúdo ainda é

\footnotetext{
1 Hegel trata, na verdade, exclusivamente da arte em seu conceito e nunca fala da "experiência estética”. Pelo fato de que nas minhas reflexões vou me referir principalmente ao momento subjetivo da arte, a saber, o da produção e da fruição, acho legítimo o uso desta expressão. Este aspecto da arte é aquele que a Fenomenologia, como ciência da experiência da consciência, expõe mais à luz.

2 G. W. F. HEGEL. Phänomenologie des Geistes. Hamburgo: Meiner, 1980, p. 354. Ed. de W. Bonsiepen, R. Heede. (GW, v. 9); idem. Fenomenologia do espírito. Trad. de P. Meneses. Petrópolis (RJ): Vozes, 2002, p. 443.
} 
inadequado: é uma unidade abstrata, incapaz de sair do eu³. Somente com a religião manifesta isto se dá, seja como a encarnação de Deus (Menschenwerdung Gottes), em que o divino vem reconhecido como o si de todos os homens, seja como a universalidade concreta e o espírito da comunidade. Na religião manifesta, contudo, é a forma que não é apropriada, porque não é conceitual: a substância que se faz sujeito é depois só representada ${ }^{4}$.

A integração acontece simplesmente pondo em relevo as recíprocas faltas dos dois momentos; pois ela não deve ser construída pelo pensamento, mas se recompõe em sua transparência depois que o pensamento a desagregou. Da unidade posta em relevo emerge finalmente o saber absoluto ${ }^{5}$.

Nesse nível não existe mais alteridade para conquistar, nem as figuras da consciência têm mais razão de ser: "o espírito ganhou o puro elemento do seu ser aí, o conceito" ${ }^{\text {. }}$.

A possibilidade de empreendimento de um saber conceitual, ou seja, científico, do Absoluto, desideratum posto na introdução, é, portanto, legítima. Fica, contudo, ainda um dever por cumprir: o espírito que sabe de si mesmo na forma do conceito deve retirar o próprio si como "figura", e este extremo sacrifício, esta última extrusão, é "o processo de vir a ser [...] na forma do livre acontecer contingente" , isto é, o espírito vira natureza e história.

Mas nesse ponto estamos já além da Fenomenologia, num terreno em que é introduzida a ciência, entramos, assim, na ciên-

3 G. W. F. HEGEL. Phänomenologie..., op. cit., p. 427; idem. Fenomenologia.., op. cit., p. 534 .

4 Idem. Phänomenologie..., op. cit., p. 428; idem. Fenomenologia..., op. cit., p. 535.

5 Id., ibid.; idem. Phänomenologie..., op. cit., p. 428 . O caráter incompleto e, em geral, pouco persuasivo da argumentação hegeliana nesses últimos passos da Fenomenologia é sublinhado por H. F. FULDA (cf. Das Erscheinende absolute Wissen. In: K. WIEWEG, Ed. Hegels Phänomenologie des Geistes. Ein kooperativer Kommentar zu einem Schlüsselwerk der Moderne. Frankfurt am Main, 2008, p. 601-24, em particular a p. 604).

6 Idem. Phänomenologie..., op. cit., p. 432; idem. Fenomenologia..., op. cit., p. 542.

7 Idem. Phänomenologie..., op. cit., p. 434; idem. Fenomenologia..., op. cit., p. 543-4. 
cia verdadeira e própria ${ }^{8}$.

A ciência como tal, isto é, o sistema da filosofia, deverá proceder com outras regras, tendo outros objetivos, com respeito à Fenomenologia, deverá recomeçar do início, com nova espontaneidade. Se é verdade, todavia, que o espírito parece recomeçar a sua formação com base em si mesmo, ele mostra-se involuntariamente já elevado (aufgehoben) a um ponto de vista superior. $\mathrm{O}$ itinerário cumprido vai assim ocultar-se na consciência, mas esta ocultação não é total, pois o caminho fenomenológico é conservado na forma peculiar da Er-innerung 9 .

Infelizmente não é possível manter, na tradução portuguesa de Er-innerung, o ressoar do movimento do in sich-gehen do "adentrar-se-em-si" ${ }^{10}$ do espírito, que, por sua vez, sugere a associação com o movimento próprio da consciência, a qual volta a si mesma depois de cada alienação. A Er-innerung que é re-memoração e ainda mais reflexão-que-lembra, é aquele interiorizar que concerne ao ganho do espírito e permite não apenas que ele não venha perdido, embora o saber absoluto, como tal, persiga já outros destinos e métodos com respeito à Fenomenologia, mas também permite o alcance de níveis mais altos de espiritualidade, níveis tão mais altos, quanto mais numerosas e significativas são

8 Não acho que nesse ponto Hegel refira-se à necessidade, por parte das figuras fenomenológicas, de uma confrontação com a temporalidade e a história. Pois esta necessidade já está implicada no próprio processo fenomenológico e exprime-se no virar espírito da consciência. Com o aparecer do espíirito, aparece também um mundo em que o espírito deve-se desenvolver. A confrontação com a história é uma tarefa que já foi desenvolvida; agora, o ponto da questão é a alienação do conceito de si mesmo. Sobre este ponto, cf. L. SIEP. Phänomenologie des Geistes. Ein einführender Kommentar zu Hegels Differenzschrift und Phänomenologie des Geistes. Frankfurt am Main: Suhrkamp, 2000, p. 254-8.

${ }_{9}$ G. W. F. HEGEL. Phänomenologie..., op. cit., p. 433; idem. Fenomenologia..., op. cit., p. 544. Sobre a importância do conceito de Er-innerung para compreender a experiência da consciência fenomenológica como experiência unitária, cf. R. BEUTHAN. Hegels phänomenologischer Erfahrungsbegriff. In: K. WIEWEG (Ed.). Hegels Phänomenologie des Geistes. Ein kooperativer Kommentar zu einem Schliusselwerk der Moderne. Frankfurt am Main, 2008, p. 79-94.

10 G. W. F. HEGEL. Phänomenologie.., op. cit., p. 433; idem. Fenomenologia.., op. cit., p. 544 . 
as experiências do espírito. A Er-innerung nos constitui, indelével como um horizonte do qual não se pode sair e que constantemente nos condiciona.

A Er-innerung, portanto, não coincide com o saber absoluto ${ }^{11}$, que como tal é a forma do saber conceitual que já virou ciência; mas é a conservação, digamos assim, do esforço para atingir o conceito, e também sua condição indispensável: graças a sua capacidade de "adentrar-se-em-si" é possível colher da experiência histórica e espiritual tudo isso que é essencial e de organizá-lo, assimilando-o segundo seu significado na vida do espírito. Neste sentido, enquanto re-memoração, memória que conserva, a Er-innerung é também indispensável premissa da história, como evidencia Hegel terminando a Fenomenologia ${ }^{12}$.

Procuraremos demonstrar como o conceito de Er-innerung é fundamental para compreender a experiência artística em geral.

\section{O traidor da substância}

Antes de continuar na análise da Er-innerung em relação à experiência artística, é necessário um rápido retorno dentro da Fenomenologia, e mais precisamente no interior do momento "Religião", até a seção dedicada ao tema da religião da arte. Não pretendo deter-me por completo nesta seção tão rica e atraente, vou em vez disso oferecer um rápido quadro e tratar só alguns elementos particularmente interessantes para os fins de minha argumentação ${ }^{13}$.

A arte é examinada na Fenomenologia como religião da arte:

11 Sobre a relação entre saber absoluto e ciência nos termos de Er-innerung e Gedächtnis, cf. F. CHIEREGHIN. Dialettica dell'assoluto e ontologia della soggettività in Hegel. Dallideale giovanile alla Fenomenologia dello spirito. Trento: Pubblicazioni di Verifiche, 1980, p. 440-9.

12 Id., ibid.

${ }_{13}$ Para um comentário sintético, mas exaustivo da Fenomenologia, veja-se: F. CHIEREGHIN. La Fenomenologia dello spirito. Introduzione alla lettura. Roma: Carrocci, 1998; sobre a religião da arte, em particular, p. 137-47. 
em particular a arte da Grécia antiga representa o momento mais alto da religião da arte. A arte dos gregos antigos não se limita a representar artisticamente os seus deuses, mas sim propriamente os cria ${ }^{14}$. A luta entre os Titãs e os deuses olímpicos, da qual essa religião clássica nasceu, teve origem na imaginação dos poetas; pois os gregos não forneceram forma artística a um conteúdo significativo já existente, e sim é a arte que, cantando-os e representando-os, deu ao mundo os seus deuses.

$\mathrm{Na}$ religião artística é posta uma relação particular de substância e sujeito ligada a algumas condições político-sociais particulares: a pólis e a liberdade dos cidadãos. O cidadão na pólis imediatamente se reconhece na substância ética, nas instituições e na religião.

Vida pública e individualidade são imediatamente unidas, a confiança com a qual os cidadãos acreditam na pólis incrementa a tranquila condescendência da pólis em relação ao emergir da subjetividade; por isso; o desenvolvimento livre da individualidade de cada um não parece ameaçar a calma da substância ética. Não obstante própria dentro dessa vida imediatamente livre, nascerá a necessidade de uma liberdade superior, a qual não pertence só ao homem como cidadão, e que levará esse mundo à sua dissolução. No momento de seu mais alto esplendor essa civilização une à harmonia tranquila da relação entre espírito ético e individual a harmonia do humano e do divino que se manifesta na arte. Este é o motivo pelo qual as formas de devoção dos oráculos e os jogos esportivos, momentos de agregação, devoção e afirmação de afiliação para a pólis, podem reentrar na “religião artística”.

$\mathrm{Na}$ produção artística, entrando como elemento natural, a matéria, responsável pela existência externa, é totalmente penetrada pelo espírito, de forma que a aparência mesma torna-se a

${ }_{14}$ G. W. F. HEGEL. Vorlesungen über die Ästhetik. Frankfurt am Main: Suhrkamp, 1970, v. I, p. 141. Ed. de E. Moldenhauer, K. M. Michel. (Werke, 3 v.; com base na edição de 1832-45). 
revelação do espírito. Por isso, a estátua que representa o deus-homem é adorada como o deus que mora na obra. Este perfeito penetrar-se de forma e conteúdo é o ideal do belo clássico, encarnado na própria escultura ${ }^{15}$.

É interessante notar que na seção que nós estamos tratando, Hegel não se detém tanto falando na estátua, nem na essência do belo da arte como compenetração perfeita de forma e conteúdo, mas sublinha, em vez disso, um aspecto que permanece na sombra, seja da Enciclopédia, seja nos Cursos de estética: a obra é produzida na consciência e feita por mãos humanas ${ }^{16}$. Não se trata certamente de um aspecto de pouca importância, todavia, tende a ficar em segundo plano, se considerado com maior atenção aquele lado, por isso a arte é representação do absoluto. Próprio ao fato de que o artista sabe ter produzido o deus, começa o movimento fenomenológico; por isso, a divindade, que depende do artista para o seu ser-aí, deve ser expressa com outros meios. O primeiro destes já denota uma espiritualização do meio expressivo, pois se passa da realidade da pedra à palavra, isto é, em primeiro lugar, ao oráculo e, depois, ao hino, que são unificados no culto. Com o culto, a essência divina desceu à autoconsciência. Nos mistérios de Baco e Ceres e nos jogos esportivos, a divindade mostra-se em sua unidade com a materialidade e a corporeidade, mas ainda apresenta algumas unilateralidades opostas, que serão reconciliadas pela poesia épica e pela tragédia. Será próprio da tragédia - na qual Hegel conseguirá entrever debaixo da máscara dos atores o princípio da subjetividade - a destruição da bela ética grega. Hegel atribui uma importância enorme à tragédia, tema que aparece duas vezes bem no itinerário fenomenológico. No momento do "Espírito", a tragédia, particularmente a Antígone ${ }^{17}$, representa as

15 G. W. F. HEGEL. Vorlesungen..., op. cit., v. I, p. 208.

16 Idem. Phänomenologie..., op. cit., p. 380; idem. Fenomenologia..., op. cit., p. 436.

17 Antígone é nomeada explicitamente, e há uma indicação implícita de Édipo (cf. idem. Phänomenologie..., op. cit., p. 293; idem. Fenomenologia..., op. cit., p. 325). Sobre a tragédia na Fenomenologia e em comparação com a forma em que ela aparece 
fissuras que se originam na pólis e que são o germe de sua dissolução; o fogo está então na crise das relações no âmbito da ética, marcando o conflito entre as leis humanas e as leis divinas. Agora, na "Religião", vem exposto o conflito que irrompe na ação trágica entre o homem e os deuses antropomórficos, de um lado, e o destino, do outro. A presença de um poder mais profundo e poderoso leva ao despovoamento do Olimpo, à impossibilidade de reconhecer-se nestes deuses, nos quais o homem grego achava a sua universalidade. Em ambas as seções da Fenomenologia nas quais a tragédia foi considerada, assiste-se à ascensão, no indivíduo, da exigência de um reconhecimento mais alto, mais universal de sua essência livre.

Por essa sua profundidade reveladora, Hegel define a forma artística da tragédia como "a noite em que a substância foi traída" ${ }^{18}$.

Mas quem é o traidor? Quem traiu a substância? Parece-me que posso afirmar, com base da leitura dessa seção da "Religião da arte", que o traidor da substância é o artista, não só o dramaturgo que anuncia a destruição de seu mundo, mas já o próprio escultor, o qual celebra a unidade harmônica deste mundo. A relação de tensão entre o artista e o substancial, que contradiz o equilíbrio tranquilo da obra e da sociedade à qual é destinada, pode-se intuir por meio de sua relação ambígua com a obra: por um lado, ele não é a vontade, fica tenso ${ }^{19}$, porque não consegue reconciliar-se com a substância em seu fazer-se objetiva; pois, quando a obra vem adorada como o divino, ele sente uma incomensurável distância do seu produto e não se reconhece mais nele ${ }^{20}$; por outro

nos Cursos de estética, cf. M. A. WERLE. A poesia na estética de Hegel. São Paulo: Humanitas, 2005, p. 243-56.

18 G. W. F. HEGEL. Phänomenologie.., op. cit., p. 378; idem. Fenomenologia.., op. cit., p. 475 .

19 Hegel fala explicitamente de "gespannte Individualität des Künstlers" (idem. Phänomenologie..., op. cit., p. 382; idem. Fenomenologia..., op. cit., p. 486).

20 Sobre o refletir-se da dialética dominação-escravidão na relação entre obra e artista, cf. M. GONCALVES. Uma concepção dialética da arte a partir da gênese do conceito 
lado, porém, diante do submeter-se por alguns devotos, ele torna-se consciente de ser o "mestre" (der Meister) ${ }^{21}$ da obra, e, portanto, do divino que aparece e que, aparecendo, é. Em seu arrogante saber advindo de ter sido ele a produzir aquilo, que os outros adoram como divino, o artista põe-se já como independente do mundo ético e dos valores daquele mundo, no qual esses deuses são reconhecidos como tais.

A Fenomenologia não explicita esse ponto, mas certamente é mérito desta obra, em relação à ilustração da arte grega na Enciclopédia e nos Cursos de estética, ter sublinhado um dinamismo interno, não só na tragédia, mas também lá onde a arte parecia ter alcançado seu ponto de maior equilíbrio: na escultura. É a subjetividade o princípio que alimenta e dissolve as formas de arte, subjetividade que não é apenas aquela do fruidor, que na obra percebe-se em sua relação com o substancial, mas também aquela do artista, que parece poder negar esta relação e que perscruta em seu íntimo em busca da origem da obra.

Da leitura dessa seção da Fenomenologia transparece a grande flexibilidade da teoria da arte de Hegel, que permite dar conta de manifestações muito diferentes e às vezes contraditórias da mesma atividade espiritual. Além da admissão de um intrínseco dinamismo próprio do mundo da arte, já dentro da mesma época histórica e do mesmo mundo ético, a concepção hegeliana da arte da Fenomenologia explica como na mesma época coabitam formas de arte que encarnam perfeitamente a própria época e formas nas quais é antecipada uma época nova, impedindo assim que se pense no desenvolvimento da arte como uma sucessão de blocos monolíticos, a saber, como se, ao instituir-se de um mundo, correspondesse imediata e exclusivamente uma determinada forma

de trabalho na Fenomenologia do espírito de Hegel. Kriterion [online], v. 46, n. 112, 2005, p. 260-72.

${ }_{21}$ G. W. F. HEGEL. Phänomenologie..., op. cit., p. 380; idem. Fenomenologia..., op. cit., p. 479 . 
de arte. Em realidade, se é verdade que a arte depende em uma medida considerável da cultura que a produziu, por outro lado, pode também manifestar esta afiliação contrastando aquele mundo que lhe deu origem. A Fenomenologia nos ensina que o artista não é simplesmente o intérprete da substância, mas demonstrou ser seu traidor no momento mais alto de sua união com ela.

\section{Er-innerung como fundamento e destino da experiência artística}

$\mathrm{Na}$ leitura da seção dedicada à religião da arte foi possível obter algumas indicações sobre a arte de um mundo, aquele da eticidade grega, que não nos pertence mais. É o próprio Hegel que sente necessidade de esclarecer a modalidade do relacionar-se a este mundo, ao mesmo tempo tão longe e tão presente. Refiro-me ao belo e bem conhecido trecho que se encontra dentro da seção "Religião revelada", no qual, antes de passar à exposição do tema da seção, Hegel reassume e comenta os resultados da seção precedente, a "Religião da arte". Ele observa em primeiro lugar que aquele mundo, da bela substância ética, está perdido para sempre, e os produtos nos quais esta se expressava, "obras das musas", são como "belos frutos caídos da árvore, que um destino amigo nos estende, como uma donzela que oferece frutos"22, e não há modo de revogar esta perda. O que, com o desaparecimento do mundo grego, fatalmente foi perdido é essencialmente a proximidade: no plano do integrar-se do sujeito na comunidade, no plano da religião, que estava imediatamente unida à vida ética do sujeito, e no plano da arte, que era manifestação desta harmonia imediata.

Sempre continuando na metáfora, Hegel afirma que terminaram a primavera e o verão da vida ética, que viram amadu-

22 G. W. F. HEGEL. Phänomenologie.., op. cit., p. 404; idem. Fenomenologia.., op. cit., p. 505. 
recer aqueles frutos, isto é, todas as condições que os produziram desapareceram: a água que os alimentou, o sol que os fez amadurecer, a terra que os manteve ${ }^{23}$. Por isso, nós não podemos saborear diretamente aqueles frutos, como os gregos fizeram, mas esses estão presentes para nós numa dimensão indireta. $\mathrm{O}$ que a metáfora representa é a própria atividade do dirigir-se ao interior, ativo durante a obtenção do saber absoluto ${ }^{24}$ : nossa relação com o passado do espírito é sempre mediada pelo sedimentar-se de suas experiências. A donzela que nos trouxe aquelas frutas é superior à natureza que as produziu, esta "é a re-cordação (Er-innerung) do espírito ainda exteriorizado (veräußerten) nelas" ${ }^{25}$. Esta bela página hegeliana não quer apenas dizer, de modo bastante banal, que cada arte é filha de seu tempo. Como já vimos na leitura do capítulo sobre o saber absoluto, a Er-innerung é a reflexão-que-lembra, esse movimento do "adentrar-se-em-si" que preserva e sedimenta as conquistas do espírito e permite, retomando a metáfora de Hegel, "recolher os frutos" do desenvolvimento da consciência, graças ao qual somos, sem querer, elevados a um grau mais alto de espiritualidade. Por isto, Hegel afirma que a donzela que nos oferece os frutos é superior à natureza que os produziu. A Er-innerung, condição própria de possibilidade da Fenomenologia, então se revela como condição de nossa relação com a arte antiga, que é essencialmente histórica. Também este ponto de chegada a uma historicidade originária da arte e de nossa relação com ela não seria, todavia, um ganho para nossa pesquisa, na medida em que não se trataria de uma consequência óbvia do assunto da historicidade da arte. Parece-me, ao contrário, ser possível afirmar que a Er-innerung é o elemento que caracteriza o nosso modo,

23 G. W. F. HEGEL. Phänomenologie.., op. cit., p. $3^{80}$; idem. Fenomenologia..., op. cit., p. 479 .

24 Idem. Phänomenologie..., op. cit., p. 404; idem. Fenomenologia..., op. cit., p. 505. 25 Idem. Phänomenologie..., op. cit., p. 404 (as palavras "Er-innerung" e "veräußerten" estão em itálico no original); idem. Fenomenologia..., op. cit., p. 505 ("re-cordação" e "exteriorizado", em itálico no original). 
moderno e contemporâneo, de relacionar-nos com a arte, não somente aquela do passado, mas também a de nossa época, tanto do ponto de vista da fruição como do da produção. Tentarei esclarecer este assunto com o apoio adicional dos Cursos de estética, em que a arte é tratada de acordo com seu desenvolvimento histórico e segundo a subdivisão das artes particulares. E em que vem analisado também o futuro, ou seja, o desenvolvimento da arte clássica e o surgimento da arte romântica, que nasce com o afirmar-se do princípio da subjetividade.

O princípio da subjetividade, que a arrogância do escultor, figurador de deuses, amorteceu e os conflitos da tragédia anunciaram, invade a história com o cristianismo, religião revelada. O divino, o Deus em si, é feito carne, nasce, vive, sofre, morre, ressuscita. Este conteúdo foi dado à arte como um acontecimento real, não é mais ela quem dá substância ao divino, quem produz o divino figurando-o, por isso Hegel afirma que isto, para nós, não "vale mais como o modo mais alto no qual se dá a verdade"26. O papel de demonstração do absoluto é mantido firme, não obstante, a arte não será mais o fulcro da vida ética de um povo, sobretudo porque uma tal vida ética não será mais possível.

26 G. W. F. HEGEL. Vorlesungen..., op. cit., v. I, p. 205; idem. Cursos de estética. v. I. Trad. de M. A. Werle. São Paulo: Edusp, 1999, p. 167. O fato de a arte não ser mais o modo mais alto de manifestação da substância, do Absoluto, originou e alimentou a famigerada teoria da "morte da arte". Na verdade, Hegel nunca quis afirmar que a arte deixou de ser uma atividade fundamental para o homem, ou que ela não tem mais razão de ser, nem quando afirma que "a arte procede além de si mesma". Pelo contrário, ele procura explicar as mudanças no mundo da arte, mudanças profundas que parecem ameaçar a existência da própria arte, mas procura mostrar que esta se redefine a si mesma continuamente. Sobre o tema da chamada morte da arte, cf. D. FORMAGGIO. La "morte dell'arte" e l'Estetica. Bolonha: Il Mulino, 1983. Contra a teoria da morte da arte na medida em que esta é uma figura do "Espírito Absoluto", cf. A. NUZZO. Hegel's "Aesthetics" as Theory of Absolute Spirit. Internationales Jahrbuch des Deutschen Idealismus, n. 4 ("Aesthetik und Philosophie"), Berlim-Nova York, 2006, p. 291-310. Ed. de K. Ameriks, J. Stolzenberg. A interpretação que A. C. Danto fornece da teoria do "fim da arte" parece-me aquela mais próxima à concepção de Hegel: cf. A. C. DANTO. After the End of Art: Contemporary Art and the Pale of History, Princeton (NJ): Princeton University Press, 1997; em particular, as p. 3-19. 


\section{A arte romântica como a volta em si}

Com a nova religião, o subjetivo deve ser concebido como o que é em si e por si mesmo e como o infinito para si mesmo. Não permitindo subsistir nenhuma realidade determinada como verdadeira, o princípio subjetivo, todavia, não se põe apenas negativamente, na simples oposição contra a realidade, não a ignora simplesmente, mas fixa a exigência de uma unidade mais alta, que contém em si mesma estas divisões como resolvidas ${ }^{27}$.

Nós vimos que, na arte clássica, o espiritual penetra completamente a sua aparência externa, espiritualiza o natural na união imediatamente perfeita de forma e conteúdo e transforma-se na realidade adequada ao espírito, tudo compondo uma mesma individualidade substancial. A imediata unidade do divino com a sua realidade é assim tão perfeita, que estes não têm autonomia nenhuma um em relação à outra: o deus pode mostrar-se a si mesmo somente na estátua, a estátua não pode representar ninguém senão o deus. $\mathrm{Na}$ arte romântica lidamos não mais com uma individualidade substancial, mas com o espírito livre em si mesmo. Isto não se encontra realizado de modo mais perfeito na exterioridade, por isso surge uma divisão entre o subjetivo em si mesmo e a aparência externa. A afirmação do princípio da subjetividade exige, além desta separação, uma conciliação mais alta, que, porém, não virá mais da procura no exterior, e sim de uma busca efetuada no elemento interior, decretando assim maior autonomia recíproca a estes dois elementos. Com o princípio da subjetividade, a objetividade não é mais procurada no exterior, no sensível, mas cada um a descobre em si próprio, enquanto o espírito torna-se certo de si mesmo só ao regressar do exterior ao interior ${ }^{28}$. Forma

${ }_{27}$ G. W. F. HEGEL. Vorlesungen..., op. cit., v. II, p. 127-8; idem. Cursos de estética..., op. cit., v. II, p. 251-2.

28 Idem. Vorlesungen..., op. cit., v. II, p. 138-9; idem. Cursos de estética..., op. cit., v. II, p. 260-1. 
e conteúdo, externo e interno, aparência e substância não devem mais encontrar a perfeita unidade na arte, como aconteceu na Grécia antiga. Em consequência disso o artista adquire uma certa autonomia no que diz respeito à escolha da matéria de suas obras.

Para evitar equívocos, é necessário esclarecer que o par de termos "forma" e "conteúdo" não coincide com tudo o que um leitor contemporâneo poderia pensar ser a forma e o conteúdo de uma obra de arte. À concepção hegeliana da forma não interessa, como se pensaria hoje, simplesmente o conjunto de critérios formais com que algo é representado: tanto "o que" é representado quanto o "como", a modalidade na qual é representado, correspondem àquilo que Hegel chama de "externo". Por "conteúdo", ou "interno", Hegel entende algo muito amplo, que compreende tudo aquilo a que o artista se refere como algo substancial, por isto ele fala de "divino", independentemente do fato de o artista ser crente ou não; em geral, o "interno" da obra de arte reflete o modo pelo o qual o artista entende a essência ética na qual vive, o modo de acordo com o qual ele sente e vive o seu tempo. Também na arte romântica o conteúdo tem que ser o substancial ou o divino; se isto, na religião revelada, levou a um conteúdo mais alto, não encontrou, porém, forma alguma que o pudesse realizar externamente. Por isso, o exterior, a forma, na arte romântica torna-se um elemento não essencial. A primeira consequência deste desequilíbrio é que começam a ser objetos da representação também elementos da realidade comum ${ }^{29}$. Na arte grega tudo o que era representado situava-se numa dimensão ideal, distante da banalidade do dia a dia, e a humanidade do deus grego era purificada de todo elemento de imperfeição e casualidade. Depois, na arte romântica, e sempre com base nessa divisão de externo e interno, é possível conceder espaço também ao feio ${ }^{30}$. Isto significa

${ }_{29}$ G. W. F. HEGEL. Vorlesungen..., op. cit., v. II, p. 139; idem. Cursos de estética..., op. cit., v. II, p. 260-1.

30 Idem. Vorlesungen..., op. cit., v. II, p. 139; idem. Cursos de estética..., op. cit., v. II, p. $260-1$. 
que o artista romântico, para representar o divino, não escolherá exclusivamente assuntos divinos e terá a liberdade de não os representar simplesmente com caráter e em situações propriamente divinas. Pensamos, por exemplo, para nos limitar às artes figurativas, nas representações do Cristo crucificado. Neste caso, é necessário representar o divino por meio da figura humana, como já acontecia na arte grega, isto, porém, não é feito mais guardando-se uma imortal distância em relação a tudo o que é humano e provisório. Diferentemente disso, a imagem de uma tortura pode assumir a forma de um conteúdo tendo base na religião revelada: longe do céu e desprezado pelos homens, aqui na terra Deus é morto e humilhado.

As representações de um deus desfigurado pela dor, sangrando e derrotado não teriam sido imagináveis na arte grega ${ }^{31}$. O artista romântico não purifica a exterioridade, mas lhe dá de ombros, livrando-se da sujeição a esta ${ }^{32}$. Ele pode representá-la mais ou menos fielmente, ampliar ou reduzir o aspecto de seus assuntos. Não se trata de desprezo pelas aparências, nem de enclausuramento aristocrático, mas de ter consciência de que o essencial a ser representado está em primeiro lugar na profundidade do espírito. Ao dar de ombros à realidade, esse pintor ou escultor volta-se para si mesmo, para sua autonomia de homem e de artista, ou, poderíamos dizer, ele reflete lembrando. Pois me parece, na realidade, inegável que esse voltar-se para si do artista é próximo do movimento próprio da Er-innerung.

Poderia, entretanto, contestar a interpretação segundo a qual Hegel, mostrando o "adentrar-se-em-si" do espírito, em realidade quisesse simplesmente indicar uma atenção maior da parte desse

${ }_{31}$ G. W. F. HEGEL. Vorlesungen..., op. cit., v. II, p. 132-5; idem. Cursos de estética..., op. cit., v. II, p. 255-8.

32 Hegel traz o exemplo da pintura holandesa, que representa o ingressar do quotidiano na arte. Para ele, isto é a consequência da Reforma protestante e da vitória contra os espanhóis de Felipe II (idem. Vorlesungen..., op. cit., v. III, p. 123-31, em particular, p. 128; idem. Cursos de estética..., op. cit., v. III, p. 270-6, em particular, p. 274). 
tipo de arte à expressão dos sentimentos próprios do artista. Na realidade, este elemento está presente de modo inconfundível, mas não é aquele dominante, também porque, é oportuno lembrar, com “arte romântica” não se pretende significar exclusivamente a arte que se impõe a partir da segunda metade do século XVIII, mas toda a produção artística que se inicia na época paleocristã, vindo até os tempos do filósofo. Ou melhor, Hegel parece mostrar, caracterizando a arte romântica com o movimento de "adentrar-se-em-si" do espírito, a consecução de um grau mais alto de reflexividade na produção e na fruição da arte. Isto, como vimos, é consequência da afirmação do princípio da subjetividade, que, a partir de seu impor-se na história, produziu um nível sempre mais alto de autoconsciência no sujeito, até alcançar a moralidade kantiana, na qual o sujeito não reconhece nada como válido e verdadeiro fora de tudo o que sua consciência lhe impõe. O fato de ter de submeter tudo ao filtro do próprio julgamento não contradiz a substancialidade da religião, mas realiza uma possibilidade íntima sua e reflete-se em uma atitude artística mais crítica e destacada.

Essa atitude reflexiva revela-se também na relação com a tradição, pois se, de um lado, o artista e o fruidor, ou o crítico, só olham dentro de si, procurando em si o substancial, de outro lado, adentrando-se em si, eles não podem não se confrontar com tudo o que está sedimentado no íntimo ${ }^{33}$. Então, a Er-innerung é o elemento próprio da arte romântica, como pesquisa de uma dimensão mais íntima e profunda, e também como filtro crítico seja com respeito à própria experiência pessoal, seja com respeito à relação com a tradição, no sentido da sedimentação das experiências do espírito.

33 Pense-se, por exemplo, na arte do Renascimento que se inspirou no classicismo, originando uma forma de arte nova e diferente (G. W. F. HEGEL. Vorlesungen..., op. cit., v. III, p. 127; idem. Cursos de estética..., op. cit., v. III, p. 273-4). 


\section{A substância não se pode mais trair}

Como dissemos, um dos principais méritos da teoria hegeliana da arte é que individualiza linhas de tendência, filosóficas, religiosas, político-sociais, de amplo alcance, permitindo uma leitura dinâmica do desenvolvimento da arte em diferentes épocas e das várias artes em seu desenvolvimento temporal. Muito interessante em relação à leitura aqui proposta revela-se a análise do fim da arte romântica, baseada nessa teoria ${ }^{34}$.

Considerando a amplitude da periodização da arte que Hegel fornece e sua relativa flexibilidade, quando ele fala do fim da forma de arte romântica, que está começando em sua época, é possível pensar que esse momento do desenvolvimento artístico chegue a nos envolver diretamente.

O momento crítico que anuncia a dissolução da arte romântica, de acordo com Hegel, pode ser recuado ao tempo do nascimento do romance moderno. Em seu Dom Quixote, Cervantes mostra a transformação, no sentido da dissolução, dos valores cavalheirescos, representados na loucura do protagonista. Esses valores - como a honra, o amor e a fidelidade - não são, pois, virtudes éticas, mas interessam como ilustração da subjetividade tornando-se independente da mediação de Deus, são, isto é, um desenvolvimento ulterior em que o princípio se afirma, um desenvolvimento ainda amarrado à representação religiosa ${ }^{35}$. Cervantes anuncia a extinção de um mundo ao representar de modo cômico a cega adesão a seus valores, a teimosia com que o protagonista mantém-se fiel a um mundo que não existe mais ${ }^{36}$.

Esse dirigir-se contra o conteúdo denota o fim, que terminará

34 G. W. F. HEGEL. Vorlesungen..., op. cit., v. II, p. 231-42; idem. Cursos de estética..., op. cit., v. II, p. $338-46$.

35 Idem. Vorlesungen..., op. cit., v. II, p. 169-93; idem. Cursos de estética..., op. cit., v. II, p. 287-310.

36 Idem. Vorlesungen..., op. cit., v. II, p. 216-9; idem. Cursos de estética..., op. cit., v. II, p. $325-8$. 
muitos séculos depois, da arte romântica. Se, na realidade, até este ponto o essencial era que o artista se referisse ao substancial, agora esta referência perde a centralidade. Na passagem da arte clássica para a romântica, o divino não podia mais ser entendido ao modo da Grécia antiga, porque, com os desdobramentos da história, era assegurado um princípio mais profundo e universal que impunha uma mudança radical de paradigma. A religião revelada teve a tarefa de afirmar este princípio, e a arte desenvolveu-se em correspondência com a imposição deste. Agora, ou seja, na época em que Hegel escreve, a religião não é mais o modo mais alto de representar o divino; em vez dela, é o pensamento que deve assumir até o final esta missão ${ }^{37}$. O pensamento liga-se à subjetividade idêntica a si mesma em sua liberdade e à objetividade mais real.

Embora o conteúdo seja o mesmo, impõe-se um novo modo de apresentar-se que não podia deixar de condicionar a arte. $\mathrm{O}$ fato de o medium expressivo da arte ser o sensível põe a arte pós-romântica em uma posição decididamente desequilibrada em comparação com o pensamento, por isto esta precisa sempre mais do conceito para expressar-se. O elemento sensível da arte vem integrado ao conceito e por ele se faz transparente: seja o fruidor da arte, seja o artista devem cada vez mais estabelecer relações com a dimensão do pensamento para compreender e para fazer entender a arte. Por isto as informações sobre a obra, sobre a intenção do artista, mostram-se sempre mais relevantes no momento de entrar em contato com uma arte qualquer. Paralelamente a tudo isso, cresce de importância o papel do crítico que interpreta de acordo com o conceito, assim como o grau de preparação cultural do público torna-se decisivo para que a arte produza seus efeitos ${ }^{38}$.

37 G. W. F. HEGEL. Vorlesungen..., op. cit., v. II, p. 143-4; idem. Cursos de estética.., op. cit., v. II, p. 265-7.

38 Sobre a importância dos críticos na arte contemporânea e na determinação desta como "arte conceitual", cf. A. C. DANTO. After the End..., op. cit. Já Oscar Wilde havia se manifestado a respeito do fenômeno da crescente importância dos críticos, 
Esta preponderância do conceito sobre a representação intuitiva pode ajudar-nos a entender por que as vanguardas do século XIX preocuparam-se em primeiro lugar com definir o que era para eles a arte por meio de manifestos, em lugar de manifestar essas mesmas ideias diretamente, imediatamente, mas com as obras, com a arte ${ }^{39}$.

A arte romântica, na dimensão da Er-innerung, ou seja, do adentrar-se-em-si mesmo, já tinha encontrado maior liberdade de expressão, dedicando-se também a assuntos profanos, e agora radicalizava essa liberdade de um ponto de vista externo, oferecendo um espectro quase infinito de possibilidades expressivas ao artista. Depois de ficar livre da forma, a arte procura livrar-se também do conteúdo. É contra o conteúdo, o qual, todavia, para o autor ainda é o substancial, que se dirige Cervantes, celebrando as ações cômicas de seu herói e anunciando assim a passagem para um outro modo de manifestar o absoluto. Na arte pós-romântica o conteúdo desaparece, pondo em crise aquela que parecia a convicção fundamental de Hegel: que o ponto essencial para a arte é o conteúdo ${ }^{40}$. Para sublinhar o valor de ruptura desse progresso, Hegel sustenta que a arte vai além de si mesma. Isto é, não vai intenso em senso de negativo, trata-se de um desenvolvimento imanente ao próprio conceito de arte, desenvolvimento em tudo e por tudo coerente com aquele movimento de volta a si mesmo, típico da Er-innerung, que já tínhamos visto em ação secretamente, na traição da substância pelo escultor, e depois abertamente, como caráter fundamental da arte romântica. Para confirmar esta interpretação, é oportuno trazer por completo uma passagem de Hegel:

tanto por tornarem paradoxalmente mais teórica a crítica das novas criações como por terem igualmente feito da crítica um pressuposto da arte (cf. O. WILDE. The Critic as Artist. Londres: James R. Osgood McIlvaine \& Co., 1891).

39 A. C. DANTO. After the End..., op. cit.

40 G. W. F. HEGEL. Vorlesungen..., op. cit., v. II, p. 231-3; idem. Cursos de estética..., op. cit., v. II, p. 337-9. 
Não obstante, a arte que vai além de si mesma é igualmente um retorno do homem a si mesmo, um descer em seu próprio peito, com o qual a arte cancela de si mesma toda limitação fixa para um círculo determinado de conteúdo e de apreensão, fazendo do humano o seu novo objeto sagrado $^{41}$.

Enquanto o artista romântico, ao “descer em seu próprio peito”, encontrou o princípio da subjetividade a que aspirava, embora submetido a uma determinação histórica, devendo afirmar-se no mundo modelando-o, o artista pós-romântico encontra sua liberdade absoluta e um mundo já compenetrado por aquele princípio, que se emancipou da representação religiosa e afirmou sua universalidade, transcendendo toda particularidade. Isto significa que as obras do artista pós-romântico não serão mais ligadas à expressão dessas realidades, mas a arte, concomitantemente com a universalização do princípio da subjetividade, terá um valor cada vez mais global, não mais comprometido à filiação a um povo ou a uma religião particular. A arte terá valor para a humanidade enquanto tal. O artista, então, não pode mais trair a substância, porque a arte já está livre deste laço com o substancial; o traidor é salvo pelo suspeito, resgatado pela possível acusação, mas para isto o seu operar é também de algum modo neutralizado tanto em sua função crítica, quanto naquela de intérprete da substância. Sendo levados para além na interpretação, poderíamos sustentar que realmente é por isto que as obras tendem sempre mais a despertar clamor, a surpreender, a transtornar: não podendo mais contrapor-se a nada do que ele reconheça como substancial, limita-se a provocar. A arte contemporânea oferece-nos inumeráveis exemplos desse processo. Retomando um exemplo comentado por Danto, consideramos aqui o Piss Christ, a obra controversa do

41 G. W. F. HEGEL. Vorlesungen..., op. cit., v. II, p. 237; idem. Cursos de estética..., op. cit., v. II, p. 341-2. 
artista nova-iorquino Andres Serrano ${ }^{42}$. Exposto pela primeira vez em 1987, despertou controvérsias, azedume e polêmicas. Trata-se concretamente da fotografia de um crucifixo que adquire um reflexo particular luminoso porque mergulhado na urina do artista. Esta obra representa exatamente o senso da perda de substância do artista: não se pode afirmar que a intenção dele tenha sido representar com esses meios a Menschenwerdung Gottes, introduzindo um elemento decididamente humano, por assim dizer, no terreno da representação do Deus cristão. Nem mesmo se pode dizer que o artista quis dar um sentido mais forte à representação da humilhação da cruz, pela qual se prepara a ressurreição. Tudo isto seria possível somente se o artista se referisse a qualquer coisa de substancial e reconhecesse este substancial também para o seu público.

Também Cervantes ridiculariza valores, no caso, os cavalheirescos, arraigados na religião, porém, o contrapor-se à substância de Serrano é diferente: aqui na escolha do assunto religioso não há o propósito de ampliar o efeito de desgosto que o espectador experimenta quando toma conhecimento do que realmente se trata, isto é, quando compreende que a representação artística foi integrada por um pensamento contendo uma informação, sem a qual a a obra resultaria completamente mal entendida.

A Er-innerung, que foi a dimensão fundamental da arte romântica, torna-se, com o afirmar do pensamento conceitual, uma manifestação mais satisfatória do conteúdo absoluto, a base da arte pós-romântica. Sem este movimento centrípeto do espírito, a arte se dissolveria na presunção ou desabaria no formalismo, que Hegel lamenta como um das piores degenerações da arte: considerar que todo o valor artístico de uma obra está no prazer proporcionado por sua forma é vergonhoso, e a esvazia de todo valor ${ }^{43}$. 
Voltar-se para si mesmo, dirigir a atenção para o homem em sua liberdade é o único saldo de oportunidade, evitando a vertigem da falta do conteúdo e sem cair no formalismo. O homem deve lembrar-se de si mesmo e lembrar-se disto, toda vez, por meio de toda obra; por isso, a obra contemporânea desperta mais reflexão que prazer, mais perguntas que respostas, tanto que a inevitável desorientação que se experimenta diante de algumas propostas não pode deixar de ser interpretada como uma forte indicação da única direção possível: aquela para dentro de si mesmo.

\section{Bibliografia}

BEUTHAN, R. Hegels phänomenologischer Erfahrungsbegriff. In: VIEWEG, K. (Ed.). Hegels Phänomenologie des Geistes. Ein kooperativer Kommentar zu einem Schlïsselwerk der Moderne. Frankfurt am Main, 2008.

CECCHINATO, G. Er-innerung e arte. Verifiche, 2009.

CHIEREGHIN, F. Dialettica dell'assoluto e ontologia della soggettività in Hegel. Dall'ideale giovanile alla Fenomenologia dello spirito. Trento: Pubblicazioni di Verifiche, 1980. . La fenomenologia dello spirito. Introduzione alla lettura. Roma: Carrocci, 1998.

DANTO, A. C. After the End of Art: Contemporary Art and the Pale of History. Princeton: Princeton University Press, 1997.

op. cit., v. II, p. 340-1. Hegel manifestou-se contra o formalismo já em seus primeiros esboços sistemáticos: cf. idem. Jenaer Systementwurfe III, Naturphilosophie und Philosophie des Geistes. Hamburgo: Meiner, 1975, p. 254. Ed. de K. Düsing, H. Kimmerle (Gesammelte Werke, v. 6). 
DANTO, A. C. The Abuse of Beauty: Aesthetics and the Concept of Art. Peru: Carus, 2003.

FORMAGGIO, D. La "morte dell'arte" e l'estetica. Bolonha: Il Mulino, 1983.

FULDA, H. F. Das Erscheinende absolute Wissen. In: VIEWEG, K. (Ed.). Hegels Phänomenologie des Geistes. Ein kooperativer Kommentar zu einem Schliusselwerk der Moderne. Frankfurt am Main, 2008.

GONÇALVES, M. Uma concepção dialética da arte a partir da gênese do conceito de trabalho na Fenomenologia do espirito de Hegel. Kriterion [online], v. 46, n. 112, 2005.

HEGEL, G. W. F. Vorlesungen über die Ästhetik. Frankfurt am Main: Suhrkamp, 1970. Ed. de E. Moldenhauer, K. M. Michel. (Werke, 3 v.; com base na edição de 1832-45). . Jenaer Systementwurfe III, Naturphilosophie und Philosophie des Geistes. Hamburgo: Meiner, 1975. Ed. de K. Düsing, H. Kimmerle. (Gesammelte Werke, v. 6).

Phänomenologie des Geistes. Hamburgo: Meiner, 1980. Ed. de W. Bonsiepen, R. Heede. (Gesammelte Werke, v. 9).

. Cursos de estética. 4 v. Trad. de M. A. Werle. São Paulo: Edusp, 1999.

. Fenomenologia do espírito. Trad. de P. Meneses. Petrópolis (RJ): Vozes, 2002.

NUZZO, A. Hegel's "Aesthetics" as Theory of Absolute Spirit. Internationales Jahrbuch des Deutschen Idealismus, n. 4 ("Aesthetik und Philosophie"), Berlim-Nova York, 2006. Ed. de K. Ameriks, J. Stolzenberg.

SIEP, L. Phänomenologie des Geistes. Ein einführender Kommentar zu Hegels Differenzschrift und Phänomenologie des Geistes. Frankfurt am Main: Suhrkamp, 2000.

WERLE, M. A. A poesia na estética de Hegel. São Paulo: Humanitas, 2005 .

WILDE, O. The Critic as Artist. Londres: James R. Osgood McIlvaine \& Co., 1891. 